КУЗНЕЦОВ Игорь Михайлович - кандидат социологических наук, ведущий научный сотрудник Института социологии Федерального научно-исследовательского социологического центра РАН (117218, Россия, г. Москва, ул. Кржижановского, 24/35, корп. 5; ingvar31@yandex.ru)

\title{
ЦЕННОСТНЫЕ ОСНОВЫ МЕЖРЕЛИГИОЗНОГО СОГЛАСИЯ ПРАВОСЛАВНЫХ И МУСУЛЬМАН РОССИИ
}

\begin{abstract}
Аннотация. В статье обосновывается подход к исследованию ценностей российского общества, позволяющий эмпирически исследовать общие ценностные основания, обеспечивающие межрелигиозное согласие мусульман и православных России. На большом объеме эмпирических данных, реализующих этот подход, показано, что согласованное восприятие текущих российских реалий представителями разных религий обеспечивается в России одинаковым традиционалистским осмыслением базовых ценностных ориентиров.
\end{abstract}

Ключевые слова: межрелигиозное согласие, традиционалистские ценностные смыслы, секулярнорациональные (модернистские) ценностные смыслы, терминальные ценности, инструментальные ценности

A ктуальность исследования ценностных основ консолидации российского общества во всем его социальном, культурном, национальном, религиозном многообразии вряд ли нуждается в специальных обоснованиях. В частности, это касается вопроса достижения межрелигиозного согласия, который является достаточно болезненным в нынешних условиях роста религиозного экстремизма в мире. При этом мы понимаем межрелигиозное согласие как согласованное восприятие и оценку представителями разных религий текущих реалий как внутри, так вне России. Одна из существенных проблем формулирования таких основ состоит в том, какой параметр общественной системы ценностей может в наибольшей мере обеспечить общность картины мира граждан России независимо от их социально-политических взглядов, этнокультурной и религиозной идентичности, разного исторического опыта пребывания в составе России и опыта контактов с другими народами, населяющими страну.

\section{Рабочая концепция исследования ценностных смыслов}

В самом упрощенном виде при поиске общих ценностных оснований консолидации граждан России можно выделить два методологических подхода. Один из них состоит в формулировании определенного списка ценностей-понятий с дальнейшим отслеживанием в эмпирическом социологическом исследовании вариаций в предпочтениях тех или иных ценностных наборов среди различных групп населения. Впервые в постсоветской России такой подход был осуществлен в рамках исследования базовых ценностей россиян [Базовые ценности россиян... 2003]. Наиболее систематическое исследование ценностей россиян в рамках такого подхода на протяжении ряда лет осуществлялось под руководством Н.И. Лапина [Лапин 2011]. Указанный подход в целом лежит в русле общемировой традиции эмпирического исследования ценностей, а наиболее авторитетными для кросс-национальных исследований в последнее десятилетие являются методики С. Шварца [Schwartz 1992], Г. Хофстеде [Hofstede 2011] и Р. Инглхарта [Инглхарт, Вельцель 2011].

Однако применение этого подхода к исследованию ценностных систем общества, а тем более к поиску общих оснований консолидации людей, ориентирующихся на различающиеся системы ценностей, является проблема- 
тичным по ряду причин. Во-первых, это практическая невозможность сформулировать логически обоснованный исчерпывающий, но в то же время ограниченный по количеству список ценностей, на что указали авторы первого исследования базовых ценностей россиян [Базовые ценности россиян... 2003: 17]. Во-вторых, понятие, обозначающее ту или иную ценность, имеет множество смыслов, отражающих видение данной ценности - от самого архаического до вполне модернизированного. Так, например, такая ценность, как семья, может пониматься как большая семья, состоящая из нескольких поколений родственников и имеющая общее хозяйство, а также как современная нуклеарная семья из двух человек, объединенных только взаимным чувством. Очевидно, что усредненная оценка респондентов с разными представлениями о характере семьи не будет достаточно информативной для оценки сходства/ различия в отношении к этой ценности. Наконец, многообразие наборов ценностей и ценностных смыслов, само собой разумеющееся для разных этнокультурных и религиозных сообществ России и, более того, находящихся на разных стадиях процесса модернизации, делает методологически неэффективным поиск ценностных оснований межнационального и межрелигиозного согласия россиян на уровне исследования списков ценностей и их содержательного наполнения.

Возможность иного, методологически более эффективного подхода к поиску общих ценностных оснований, объединяющих этнически и религиозно разнообразное население России, обнаруживается при внимательном анализе принципов изучения ценностных систем современных обществ, реализованных в уже упомянутых выше исследованиях Р. Инглхарта и отчасти Г. Хофстеде, но с некоторыми изменениями и дополнениями. Так, в концепции Р. Инглхарта типологизация ценностных систем осуществляется в пространстве, ограниченном двумя осями измерений. Первое из этих измерений отражает сравнительные различия в рамках бинарной оппозиции «традиционные ценности - секулярно-рациональные ценности», а второе - в рамках оппозиции «ценности выживания - ценности самовыражения» [Инглхарт, Вельцель 2011: 80]. Переход от «традиционных» К «секулярно-рациональным» ценностям происходит в процессе модернизации общества и последовательном отказе от религиозных норм в пользу рациональных оснований. Переход от «ценностей выживания» к «ценностям самореализации» происходит на стадии постмодерна и выражается в отказе от подчинения нормам общественной необходимости и полезности и переориентации на ценности личностной автономии. Этот второй переход обычно связывают с ростом общего уровня благосостояния и безопасности.

На наш взгляд, эти два измерения можно свести к одному: «ценности традиционализма - секулярно-рациональные ценности». Оппозиция «ценности выживания - ценности самореализации» по сути представляет разные мотивационные векторы любых ценностно ориентированных практик.

Так, актуализация какой-либо ценности (например, ценности «семья») в общественной практике может быть мотивирована и/или одобряема как способ «выживания» или как способ «самореализации», что ведет к соответствующей модификации конкретных практик в рамках семейной жизни. Это касается и распределения семейных ролей, и особенностей семейной иерархии, и контекстов сексуальных отношений между супругами. При этом сами понятия «выживание» и «самореализация» имеют разное содержательное наполнение в зависимости от системного контекста использования этих понятий. Так, в традиционалистской системе ценностей под выживанием может пониматься прежде всего поддержание стабильности и предсказуемой эволюции сообще- 
ства, а в секулярно-рациональной системе, где материальное благополучие и безопасность сообщества сами собой разумеются, под выживанием может скорее пониматься физическое выживание индивида, что отражается в максиме самоценности человеческой жизни, характерной именно для сообществ Постмодерна. То же относится и к пониманию самореализации. В традиционалистской системе ценностей под самореализацией может пониматься вклад индивида в поддержание сохранности сообщества как в плане физическом, так и в отношении его культурной идентичности, при необходимости - даже ценой собственной жизни. А в секулярно-рациональной системе - это скорее объективация (в каких-либо артефактах и/или практиках) личностной идентичности («Я-концепция») как самоценности.

В итоге в нашей рабочей концепции набор ценностей, их определенная структура в том или ином культурно-историчном сообществе остаются относительно постоянными во времени, а процесс смены ценностей сводится к изменению содержательного наполнения понятий, обозначающих общественные ценности. Эти постепенные изменения содержания той или иной ценности можно расположить между двумя полюсами - традиционалистское истолкование ценности и модернистское (секулярно-рациональное) истолкование. Таким образом, если мы хотим фиксировать промежуточные состояния в динамике ценностных систем, то уместно говорить не об особом традиционном или модернистском наборе ценностей, а о положении данной исторически и культурно определенной системы ценностей на шкале «традиционализм - модернизм». Мы определяем традиционный полюс системы ценностей как центрированный на поддержании стабильности и преемственности во времени данного сообщества, а секулярно-рациональный полюс той же системы ценностей - как центрированный на поддержании определенности и самодостаточности отдельных индивидов (независимость от сообщества) ${ }^{1}$.

Изложенный выше подход был использован при исследовании ценностных оснований консолидации россиян в рамках реализации проекта 2014-2018 гг. «Ресурс межэтнического согласия в консолидации российского общества: общее и особенное в региональном разнообразии» (грант РНФ № 14-18-01963) [Межнациональное согласие... 2016: 164-204].

Согласно полученным нами данным, современное российское сообщество никак нельзя назвать базирующимся на традиционных ценностях, что делает проблематичным широко распространенное в политологической литературе последних лет представление об имманентном традиционализме россиян в плане ценностных ориентиров и/или об «откате» российского общественного сознания на традиционалистские позиции [Паин 2011: 49-53]. По преимуществу россияне находятся в процессе переосмысления ценностных приоритетов, хотя и относительно велика доля тех, кто систематически придерживается традиционалистских интерпретаций тех или иных ценностей. Сопоставление реакций на стандартные жизненные ситуации представителей групп «традиционалистов» и тех, кто находится в процессе переосмысления ценностных смыслов, показало, что реакции «традиционалистов» более согласованы [Межнациональное согласие... 2016: 184-185]. Причем согласованность взглядов «традиционалистов» прослеживалась как для респондентов разных возрастов, так и на уровне разных регионов и национальностей. Это позволило сделать вывод, что сам по себе традиционализм в интерпретации ценностей независимо от вероятных различий в наборе ценностей и их иерархии служит одним из ключевых оснований согласованного отношения россиян к ключевым вопросам текущей жизни

\footnotetext{
${ }^{1}$ Более подробно эта концепция изложена в статье И.М. Кузнецова [Кузнецов 2017].
} 
независимо от социально-культурного многообразия, присущего российскому обществу.

Более детальный анализ полученных данных позволил также ответить на вопрос об устойчивом «традиционалистском» имидже России, несмотря на объективно небольшую долю людей, систематически придерживающихся традиционалистских ориентаций. Согласно нашим данным, россияне придерживаются «традиционалистских» ценностных ориентиров преимущественно в вопросах видения места России в мире и в вопросах, касающихся безусловного приоритета моральных норм над рациональными соображениями. Полюс «модернизма» респонденты выбирают, если речь идет об ориентирах, касающихся экономической деятельности, и инновациях, связанных с изменением принципов функционирования российской экономики. Это, например, приоритетный выбор такого ценностного ориентира, касающегося трудовой деятельности, как «тот, кто выполняет задание, должен сам принимать решения и нести за них ответственность» и значительно меньшая поддержка традиционалистского истолкования той же ценности: «начальник всегда должен принимать все решения, и он должен отвечать за все».

Ценностные системы общества имеют многоуровневую иерархическую структуру - от ценностных императивов абстрактного идеологического уровня (в традиции, идущей от М. Рокича [Rokeach 1973], их можно обозначить как «терминальные ценности») до разветвленного набора принципов повседневного поведения («инструментальных ценностей», по Рокичу), уже не столь очевидно связанных с соответствующими императивами. Если рассматривать отдельно блоки терминальных и инструментальных ценностей, то оказывается, что применительно к терминальным ценностям фиксируется широкая (на уровне 66\%) поддержка традиционалистских смыслов этих ценностей. И такая поддержка минимальна (26\%), когда речь идет об инструментальных ценностях. Отсюда был сделан вывод о том, что что терминальные ценности в процессе модернизации связанных с ними инструментальных ценностей нижних уровней постепенно перестают выполнять функцию собственно императивов (предписаний к действию) и начинают функционировать в качестве маркеров, отграничивающих российское цивилизационное пространство, и одновременно служат символами принадлежности к российскому сообществу, т.е. маркерами общероссийской идентичности [Кузнецов 2017: 24]. Иначе говоря, по мнению подавляющего большинства респондентов, причисление себя к россиянам связано с лояльностью (или, по крайней мере, с манифестацией лояльности) таким ценностным ориентирам, как признание особого, отличного от европейского пути исторического развития России, уважение к сложившимся традициям, приоритет моральных норм перед рациональной эффективностью, видение России как великой державы. Это на сегодняшний день и есть те «скрепы», которые, согласно нашим данным, консолидируют российское общество в его социальном, культурном и этническом многообразии и во многом формируют «традиционалистский» образ России. Как можно судить по нынешним российским общественным дискурсам, чем сильнее внешнее давление на Россию, тем сильнее требование демонстрировать лояльность этим ценностным императивам, чтобы быть признанным «настоящим» россиянином.

\section{Основа для межрелигиозного согласия в России}

Отдельный вопрос - насколько перечисленные выше ценностные основания могут способствовать поддержанию межрелигиозного согласия, особенно согласия между наиболее многочисленными в России религиозными сообществами православных и мусульман. До сих пор в общественном мнении попу- 
лярны представления о конфликтности христианства и ислама, наиболее категорично сформулированные С. Хантингтоном. «До тех пор, пока ислам остается исламом (каковым он и останется) и Запад остается Западом (что более сомнительно), этот фундаментальный конфликт между двумя великими цивилизациями и свойственным каждой образом жизни будет продолжаться, определяя взаимоотношения этих цивилизаций в будущем в той же мере, в какой он определял их на протяжении минувших четырнадцати столетий» [Хантингтон 2003: 332]. Не вдаваясь в детальное обсуждение концепции С. Хантингтона, можно отметить, что, во-первых, православие и ислам принадлежат к общей авраамической традиции, что уже позволяет сомневаться в их имманентной несовместимости и в том, что их вообще правомерно относить к разным цивилизационным моделям. Во-вторых, многовековая история совместного относительно бесконфликтного проживания православной и мусульманской общин в России также опровергает указанный тезис С. Хантингтона. В рамках нашего подхода к исследованию ценностей мы полагаем, что межрелигиозное согласие православных и мусульман России может быть основано на общих традиционалистских (для конфессий, утвердившихся в России) истолкованиях базовых религиозных ценностей.

\section{Методика исследования}

Возможность эмпирически проверить эту гипотезу появилась в 2017 г. в ходе опроса по программе «Ресурс межэтнического согласия в консолидации российского общества: общее и особенное в региональном разнообразии» в республике Башкортостан, где репрезентативная для республики выборка содержала примерно равное число православных и мусульман ${ }^{1}$. Мы предлагали респондентам оценить по 7-балльной шкале степень своего согласия с тем или иным из пары альтернативных бытовых суждений, отражающих разнополярные интерпретации одной и той же ценности. При этом нами были отобраны три пары суждений, отражающих терминальные ценностные ориентиры, и три инструментальные. Оценка по каждой паре суждений могла колебаться от 1 до 6 (1 - безусловное согласие с суждением традиционалистского полюса, 6 безусловное согласие с модернистским полюсом).

Ниже приведен список пар высказываний, использованных в исследовании (см. табл. 1).

На основе среднего балла, подсчитанного по сумме оценок согласия/несогласия со всеми суждениями (в диапазоне от 1 до 6) были сформированы три группы респондентов, различающихся по степени их традиционализма/модернизма. Это, во-первых, группа респондентов, ориентированных на традиционализм (средний балл - 2,9), во-вторых, группа, находящаяся в процессе трансформации ценностных смыслов (средний балл - 3,8) и группа, ориентированная на модернистские ценностные смыслы (средний балл - 4,8). В Башкортостане эти группы представлены в следующих пропорциях (см. табл. 2).

Как можно судить по данным, представленным в табл. 2, для ценностной системы Башкортостана характерна примерно равная представленность устойчивых традиционалистских диспозиций и некоторой смысловой неопределенности в истолковании ценностей. Модернистские ценностные смыслы, как и в целом по России, представлены в доле, сравнимой с ошибкой выборки. Так же,

\footnotetext{
1 Опрос проведен Республике Башкортостан в июле 2017 года по квотной районированной выборке, репрезентирующей население РБ. В выборку были включены 14 городов и 15 сельских районов, представляющих 6 геоэкономических зон республики. Были заложены квоты по полу, возрасту, образованию и национальности (башкиры, татары, русские). Всего было опрошено 1035 респондентов. Ошибка выборки составляет $\pm 3 \%$.
} 


\section{Таблица 1}

\section{Список альтернативных пар ценностных ориентиров}

\begin{tabular}{|c|c|}
\hline Ориентация на традицию & Ориентация на модернизм \\
\hline \multicolumn{2}{|c|}{ Инструментальные ценностные ориентиры } \\
\hline $\begin{array}{l}\text { 1. Государство должно обеспечивать } \\
\text { средний уровень благосостояния своих } \\
\text { граждан }\end{array}$ & $\begin{array}{l}\text { 1. Человек должен сам обеспечивать } \\
\text { себя и свою семью и не рассчитывать на } \\
\text { поддержку со стороны государства }\end{array}$ \\
\hline $\begin{array}{l}\text { 2. Нужно уметь приспосабливаться к } \\
\text { реальности, а не тратить силы на борьбу с } \\
\text { ней }\end{array}$ & $\begin{array}{l}\text { 2. Нужно активно бороться за свои } \\
\text { интересы и права }\end{array}$ \\
\hline $\begin{array}{l}\text { 3. В общественных местах надо одеваться и } \\
\text { вести себя как все, строго следуя принятым } \\
\text { правилам }\end{array}$ & $\begin{array}{l}\text { 3. В общественных местах можно одеваться } \\
\text { и вести себя, как нравится самому, лишь бы } \\
\text { не нарушать закон }\end{array}$ \\
\hline \multicolumn{2}{|c|}{ Терминальные ценностные ориентиры } \\
\hline $\begin{array}{l}\text { 4. Россия нуждается в утверждении } \\
\text { собственных национальных традиций, } \\
\text { моральных и религиозных ценностей }\end{array}$ & $\begin{array}{l}\text { 4. Россия должна двигаться к современным } \\
\text { ценностям и такому образу жизни, как в } \\
\text { развитых странах Европы }\end{array}$ \\
\hline $\begin{array}{l}\text { 5. Россия должна быть великой державой с } \\
\text { мощными вооруженными силами }\end{array}$ & $\begin{array}{l}\text { 5. Россия прежде всего должна заботиться о } \\
\text { благосостоянии собственных граждан, а не } \\
\text { стремиться к державной мощи }\end{array}$ \\
\hline $\begin{array}{l}\text { 6. Лучше добиться меньшего успеха в } \\
\text { жизни, но не переступать через моральные } \\
\text { нормы и принципы }\end{array}$ & $\begin{array}{l}\text { 6. Чтобы добиться успеха в жизни, иногда } \\
\text { приходится переступать через моральные } \\
\text { нормы и принципы }\end{array}$ \\
\hline
\end{tabular}

Таблица 2

\section{Распределение позиций на шкале «традиционализм - модернизм» в ценностной} системе жителей Башкортостана

\begin{tabular}{|c|c|}
\hline $\begin{array}{c}\text { Позиция по шкале «традиционализм } \\
\text { - модернизм» }\end{array}$ & Доля ответивших, \% \\
\hline Традиционализм & 41,6 \\
\hline Промежуточная позиция & 55,2 \\
\hline Модернизм & 3,2 \\
\hline
\end{tabular}

как и для России в целом, для Башкортостана характерна тенденция к большей традиционализации смыслов, когда речь идет о интерпретации терминальных ценностей (см. табл. 3).

Дальнейшая наша задача состоит в том, чтобы оценить, насколько согласованы или рассогласованы социально-политические диспозиции респондентов - православных и мусульман, придерживающихся традиционалистских ориентаций, в истолковании терминальных ценностей в сравнении с теми, кто находится в процессе трансформации ценностных смыслов или придерживается модернистских ориентаций ${ }^{1}$.

\footnotetext{
1 Мы сочли необходимым рассматривать промежуточную группу и группу «модернистов» в совокупности, поскольку эта последняя группа по своему размеру несопоставима с группой «традиционалистов» и сравнивать их было бы некорректно.
} 
Таблица 3

Распределение позиций на шкале «традиционализм - модернизм» в интерпретации терминальных и инструментальных ценностей

\begin{tabular}{|l|c|}
\hline \multicolumn{1}{|c|}{$\begin{array}{c}\text { Позиция по шкале «традиционализм } \\
\text { - модернизм» }\end{array}$} & Доля ответивших, \% \\
\hline \multicolumn{2}{|c|}{ Терминальные ценностные смыслы } \\
\hline Традиционализм & 52,7 \\
\hline Промежуточная позиция & 40,3 \\
\hline Модернизм & 7,0 \\
\hline \multicolumn{2}{|c|}{ Инструментальные ценностные смыслы } \\
\hline Традиционализм & 46,9 \\
\hline Промежуточная позиция & 44,2 \\
\hline Модернизм & 8,9 \\
\hline
\end{tabular}

Традиционалистская интерпретация ценностных смыслов как основание межрелигиозного согласия в России

В общественном сознании широко распространен стереотип о склонности мусульман к традиционализму. Наши данные этот стереотип не подтверждают (см. табл. 4)

Таблица 4

Распределение позиций на шкале «традиционализм - модернизм» в ценностной системе православных и мусульман Башкортостана

\begin{tabular}{|l|c|c|}
\hline \multirow{2}{*}{ Позиция по шкале «традиционализм - модернизм» } & \multicolumn{2}{|c|}{ Доля ответивших, \% } \\
\cline { 2 - 3 } & Мусульмане & Православные \\
\hline Традиционализм & 40,7 & 44,0 \\
\hline Промежуточная позиция & 55,6 & 54,0 \\
\hline Модернизм & 3,7 & 1,9 \\
\hline
\end{tabular}

В целом, ценностные диспозиции мусульман практически никак не отличаются от диспозиций православных: для обеих религиозных групп сохраняются те же пропорции, что и в общей выборке. Мусульмане оказываются не бо́льшими (и не меньшими) традиционалистами, чем православные, в обеих группах идет активный процесс переосмысления ценностных смыслов, вообще характерный для современной России.

Сопоставление оценок респондентами - мусульманами и православными - текущих социально-политических и социально-культурных реалий России показывает, что по большинству соответствующих позиций анкеты опроса статистически значимых различий не обнаруживается. Однако есть ряд ключевых для поддержания межрелигиозного согласия вопросов, относительно которых в оценках мусульман и православных обнаруживается разногласие. Ниже дан более детальный анализ оценок, данных респондентами - мусульманами и православными, - придерживающимися традиционалистских диспозиций, и представителями тех же религий, находящихся в процессе переосмысления ценностей.

Один из центральных моментов поддержания межрелигиозного согласия 
- это уровень доверия людям иной религиозной принадлежности. Как отмечал П. Штомпка, «доверие становится необходимым ресурсом, позволяющим справиться с присутствием чужих» [Штомпка 2012: 59]. В нашем исследовании представители и той и другой группы (верующие обеих религий - традиционалисты и находящиеся в процессе трансформации ценностных смыслов) демонстрируют согласованные оценки доверия мусульманам, но оценки доверия православным статистически значимо различаются (см. табл. 5).

Таблица 5

\section{Оценка доверия православным мусульманами и православными с различной интерпретацией ценностных смыслов}

\begin{tabular}{|l|c|c|}
\hline \multirow{2}{*}{ Оценка доверия православным } & \multicolumn{2}{|c|}{ Доля ответивших, \% } \\
\cline { 2 - 3 } & Мусульмане & Православные \\
\hline \multicolumn{2}{|c|}{ Традиционализм ${ }^{*}$} \\
\hline Полностью, скорее доверяют & 77,5 & 80,4 \\
\hline Полностью, скорее не доверяют & 22,5 & 19,6 \\
\hline \multicolumn{2}{|c|}{ Промежуточная позиция и модернисть } \\
\hline Полностью, скорее доверяют & 68,0 & 75,7 \\
\hline Полностью, скорее не доверяют & 32,0 & 24,3 \\
\hline \multicolumn{2}{|c|}{ В целом по массиву ${ }^{* * *}$} \\
\hline Полностью, скорее доверяют & 72,9 & 78,4 \\
\hline Полностью, скорее не доверяют & 27,1 & 21,6 \\
\hline
\end{tabular}

*Асимптотическая значимость хи-квадрат Пирсона $\geqslant 0,397$

** Асимптотическая значимость хи-квадрат Пирсона $\leqslant 0,013$

*** Асимптотическая значимость хи-квадрат Пирсона $\leqslant 0,013$

Как видно из приведенных в табл. 5 данных, мусульмане и православные с традиционалистскими диспозициями статистически не различаются в своих оценках уровня доверия, в то время как представители тех же религий, находящиеся в процессе трансформации ценностных смыслов, расходятся в своих оценках доверия православным: мусульмане склонны им доверять в меньшей степени, чем православные. Это сказывается и на общей картине разногласий мусульман и православных по этому вопросу.

Нами также обнаружена рассогласованность оценок мусульман и православных в некоторых моментах их видения России и ее будущего. Так, есть различия в оценке того, предпринимаются ли властями усилия, направленные на возрождение России как «великой державы» (см. табл. 6).

Здесь мы также видим, что при относительной согласованности оценок власти мусульманами и православными, придерживающимися традиционалистских ценностных смыслов, фиксируется рассогласованность таких оценок во мнениях мусульман и православных, находящихся в стадии трансформации ценностных смыслов, что дает рассогласованность оценок усилий власти мусульманами и православными в целом по массиву.

Также наблюдается рассогласованность православных и мусульман в оценке ими некоторых важных для многонациональной России параметров групповой идентичности (см. табл. 7).

На фоне практически одинаковой оценки ощущения близости с людьми своей национальности у мусульман и православных с традиционалистскими 
Таблица 6

Оценка усилий власти по возрождению России как «великой державы» мусульманами и православными с различной интерпретацией ценностных смыслов

\begin{tabular}{|l|c|c|}
\hline \multirow{2}{*}{ Оценка усилий власти } & \multicolumn{2}{|c|}{ Доля ответивших, \% } \\
\cline { 2 - 4 } & Мусульмане & Православные \\
\hline \multicolumn{3}{|c|}{ Традиционализм ${ }^{*}$} \\
\hline Такие усилия есть & 30,5 & 25,0 \\
\hline Таких усилий нет & 69,5 & 75,0 \\
\hline \multicolumn{3}{|c|}{ Промежуточная позиция и модернисты ${ }^{* *}$} \\
\hline Такие усилия есть & 37,4 & 26,5 \\
\hline Таких усилий нет & 62,6 & 73,5 \\
\hline \multicolumn{3}{|c|}{ В целом по массиву*** } \\
\hline Такие усилия есть & 34,0 & 25,6 \\
\hline Таких усилий нет & 66,0 & 74,4 \\
\hline
\end{tabular}

*Асимптотическая значимость хи-квадрат Пирсона $\geqslant 0,208$

** Асимптотическая значимость хи-квадрат Пирсона $\leqslant 0,035$

*** Асимптотическая значимость хи-квадрат Пирсона $\leqslant 0,012$

Таблица 7

\section{Ощущение близости с людьми своей национальности мусульманами и православными с различной интерпретацией ценностных смыслов}

\begin{tabular}{|c|c|c|}
\hline \multirow{2}{*}{ Ощущение близости } & \multicolumn{2}{|c|}{ Доля ответивших, \% } \\
\cline { 2 - 3 } & Мусульмане & Православные \\
\hline \multicolumn{3}{|c|}{ Традиционализм $^{*}$} \\
\hline В значительной степени & 38,5 & 30,3 \\
\hline \multicolumn{3}{|c|}{ Промежуточная позиция и модернисты } \\
\hline В значительной степени \\
\hline \multicolumn{3}{|c|}{34,3} \\
\hline В знелом по массиву ${ }^{* * *}$ \\
\hline \\
\hline
\end{tabular}

*Асимптотическая значимость хи-квадрат Пирсона $\geqslant 0,138$

** Асимптотическая значимость хи-квадрат Пирсона $\leqslant 0,005$

*** Асимптотическая значимость хи-квадрат Пирсона $\leqslant 0,002$

ценностными диспозициями особенно заметна небольшая доля переживающих чувство близости со своей национальностью православных по сравнению с мусульманами в группе тех, кто еще не определился в своих ценностных диспозициях.

Наконец, между мусульманами и православными Башкортостана существует рассогласованность в оценке такого важного аспекта восприятия межнациональной ситуации в республике, как влияние национальной принадлежности на возможность занять высокий пост в органах власти республики (см. табл. 8). 
Таблица 8

Оценка влияния национальной принадлежности на возможность занять высокий пост в органах власти мусульманами и православными с различной интерпретацией ценностных смыслов

\begin{tabular}{|l|c|c|}
\hline \multirow{2}{*}{$\begin{array}{c}\text { Влияет ли национальность на возможность занять } \\
\text { высокий пост в органах власти? }\end{array}$} & Доля ответивших, \% \\
\cline { 2 - 3 } & Мусульмане & Православные \\
\hline \multicolumn{3}{|c|}{ Традиционализм } \\
\hline Да & 42,2 & 48,1 \\
\hline Нет & 57,8 & 51,9 \\
\hline \multicolumn{3}{|c|}{ Промежуточная позиция и модернисть ${ }^{* *}$} \\
\hline Да & 39,3 & 54,8 \\
\hline Нет & 60,7 & 45,2 \\
\hline \multicolumn{3}{|c|}{} \\
\hline Да & 40,8 & 51,0 \\
\hline Ветелом по массиву & \\
\hline
\end{tabular}

*Асимптотическая значимость хи-квадрат Пирсона $\geqslant 0,232$

** Асимптотическая значимость хи-квадрат Пирсона $\leqslant 0,005$

*** Асимптотическая значимость хи-квадрат Пирсона $\leqslant 0,005$

Здесь, как и в других рассмотренных выше случаях общей рассогласованности оценок текущей ситуации мусульманами и православными, исключительный вклад в эту рассогласованность вносят верующие, находящиеся в процессе трансформации своих ценностных диспозиций. В данном случае это православные, которые оценивают влияние национальности на занятие высоких постов в республике Башкортостан значительно выше, чем мусульмане, и даже несколько выше, чем православные с традиционалистскими диспозициями.

В итоге мы можем сделать вывод, что согласованное восприятие текущих российских реалий представителями разных религий обеспечивается в России одинаковым осмыслением ценностных ориентиров. В данном случае это осмысление традиционалистского характера, что вполне логично, поскольку вектор традиционалистского осмысления ценностных ориентиров состоит в обеспечении стабильного существования сообщества - не только своего религиозного, но и российского, в котором они живут. А стабильность этого последнего невозможна без согласованного восприятия ключевых общероссийских реалий представителями всех религий России.

Статья подготовлена при поддержке гранта РНФ № 14-18-01963-П «Ресурс межэтнического согласия в консолидащии российского общества: общее и особенное в региональном разнообразии».

\section{Список литературы}

Базовые иенности россиян. Социальные установки. Жизненные стратегии. Символы. Мифы (отв. ред. А.В. Рябов, Е.Ш. Курбангалиева). 2003. М.: Дом интеллектуальной книги. 448 с. 
Инглхарт Р., Вельцель К. 2011. Модернизация, культурные изменения и демократия: Последовательность человеческого развития. М.: Новое издательство. 464 с.

Кузнецов И.М. 2017. Ценностные маркеры культурно-исторической идентичности россиян. - Вестник Института сощиологии. № 22. С. 12-31.

Лапин Н.И. 2011. Социокультурные факторы российской стагнации и модернизации. - Социс. Социологические исследования. № 9. С. 3-18.

Межнациональное согласие как ресурс консолидации российского общества (отв. ред. Л.М. Дробижева). 2016. М.: ИС РАН. 400 с.

Паин Э.А. 2011. Волновая природа подъема традиционализма на рубеже XXXXI веков. - Общественные науки и современность. № 2. С. 43-56.

Хантингтон С. 2003. Столкновение цивилизаций (пер. с англ. Т. Велимеева, Ю. Новикова). М.: АСТ. 603 с.

Штомпка П. 2012. Доверие - основа общества. М.: Логос. 445 с.

Hofstede G. 2011. Dimensionalizing Cultures: The Hofstede Model in Context. Online Readings in Psychology and Culture. Unit 2. URL: http://scholarworks.gvsu. edu/orpc/vol2/iss1/8 (accessed 02.04.2018).

Rokeach M. 1973. The Nature of Human Values. N.Y.: Free Press. 437 p.

Schwartz S.H. 1992. Universals in the Content and Structure of Values: Theory and Empirical Tests in 20 Countries. - Advances in Experimental Social Psychology (ed. by M. Zanna). N.Y.: Academic Press. Vol. 25. P. 1-65.

\section{VALUE FOUNDATIONS OF INTERRELIGIOUS CONSENT OF ORTHODOX CHRISTIANS AND MUSLIMS OF RUSSIA}

\footnotetext{
Abstract. The article describes the working concept of the study of common value foundations for the consolidation of Russian citizens who have different ethno-cultural and religious backgrounds. The essence of the concept is that the set of values, their specific structure in a particular cultural and historical community, remains relatively constant in historical time, whereas the process of value drift is regarded as a change in the content of concepts that denote social values. These gradual changes in the content of values can be located between two poles - a traditionalist interpretation of value and a modernist (secular-rational) interpretation. The empirical base of the research is the data of a representative survey of residents of the Republic of Bashkortostan within the framework of the project «The Resource of Interethnic Consent in the Consolidation of Russian Society: General and Special in Regional Diversity). The main conclusion of the study is that the coordinated perception of the current Russian realities by representatives of different religions is ensured in Russia by the same traditionalist interpretation of the basic value orientations.

Keywords: interreligious consent, traditionalist value meanings, secular-rational (modernist) value meanings, terminal values, instrumental values
} 